\title{
Mapping Collaborative Relations among Canada's Chronic Disease Prevention Organizations
}

\section{Cartographie des relations de collaboration entre les organismes canadiens de prévention pour les maladies chroniques}

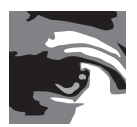 \\ DAMIEN CONTANDRIOPOULOS, PHD \\ Faculty of Nursing, University of Montreal \\ University of Montreal Public Health Research Institute (IRSPUM) \\ Montreal, QC \\ NANCY HANUSAIK, PHD \\ Hospital Research Centre (CRCHUM) \\ University of Montreal \\ Montreal, QC \\ KATERINA MAXIMOVA, PHD \\ Department of Public Health Sciences \\ University of Alberta \\ Edmonton, $A B$ \\ GILLES PARADIS, MD, FRCPC \\ Department of Epidemiology, Biostatistics and Occupational Health \\ McGill University, \\ Institut national de santé publique du Québec (INSPQ) \\ Montreal, QC \\ JENNIFER L. O'LOUGHLIN, PHD \\ Hospital Research Centre (CRCHUM), University of Montreal \\ Institut national de santé publique du Québec (INSPQ), \\ Department of Social and Preventive Medicine, University of Montreal \\ Montreal, QC
}




\begin{abstract}
In the field of chronic disease prevention (CDP), collaborations between organizations provide a vital framework for intersectoral engagement and exchanges of knowledge, expertise and resources. However, little is known about how the structures of preventive health systems actually articulate with CDP capacity and outcomes. Drawing upon data from the Public Health Organizational Capacity Study - a repeat census of all public health organizations in Canada - we used social network analysis to map and examine interorganizational collaborative relationships in the Canadian preventive health system. The network of relationships obtained through our study shows that provincial boundaries remain a major factor influencing collaborative patterns. Not only are collaborations scarce on the interprovincial level but they are also mostly limited to links with federal and multi-provincial organizations. Given this finding, federal or multi-provincial organizations that occupy central bridging positions in the Canadian CDP collaborative structure should serve as key players for shaping CDP practices in the country.
\end{abstract}

\title{
Résumé
}

Dans le domaine de la prévention des maladies chroniques (PMC), la collaboration interorganisationnelle est un processus fondamental pour l'action intersectorielle ainsi que pour l'échange de connaissances, d'expertise et de ressources. Cependant, peu de connaissances existent sur les liens entre la structure de ces réseaux de collaboration et la capacité d'action ainsi quavec les résultats de la PMC. En nous appuyant sur des données tirées du Public Health Organizational Capacity Study - un recensement de tous les organismes canadiens de santé publique - nous avons utilisé des méthodes dérivées de l'analyse des réseaux sociaux pour cartographier et examiner les relations de collaboration interorganisationnelle dans le domaine de la PMC. Les résultats de notre étude montrent que les frontières provinciales demeurent un facteur d'influence important sur les schémas de collaboration. Non seulement les relations sont-elles rares au niveau interprovincial, mais elles se limitent presque exclusivement à des liens entre les organisations fédérales et multiprovinciales. À la lumière de ces résultats, les organisations fédérales et multiprovinciales qui occupent une position centrale dans la structure canadienne de collaboration pour la PMC devraient agir comme joueurs clés dans l'élaboration des pratiques de PMC au pays.

\section{Introduction}

Promoting collaboration among key stakeholders is one of the most significant strategies to ensure effective public health practice (Birt and Foldspang 2011 [ASPHER]; Bjegovic-Mikanovic et al. 2014 [WHO]; CDC 2015; PHAC 2007), and recent evidence suggests the numbers and types of organizations engaged in collaborative public health activities are increasing (Mays and Scutchfield 2010; Simon and Fielding 2006). In the area of chronic disease prevention (CDP), these collaborations provide a vital framework for exchanging information, for sharing knowledge, expertise and resources and for intersectoral engagement (Butterfoss et al. 1993; NCCDH 2010; Roussos and Fawcett 2000). 
The Canadian public health system is complex and has been described as a "grouping of multiple systems with varying roles, strengths and linkages" (Frank et al. 2003). The preventive health system (i.e., the segment of the public health system engaged in primary CDP and promotion of tobacco control, physical activity and healthy eating) comprises many organizations that vary in size, mission, resources and jurisdictions (Hanusaik et al. 2010, 2014). While public health units constitute half the Canadian preventive health system and frequently serve as leaders for prevention activities (Varda and Retrum 2012), other organizations within the system also provide public health services and play vital roles in CDP. These include government departments, non-profit and non-governmental organizations, para-governmental agencies, resource centres and grouped organizations (i.e., coalitions and alliances) with permanent or long-term CDP mandates, among others. The numbers and types of interorganizational collaborations in which these 'core' CDP organizations engage depend on numerous factors, including the type of CDP activities undertaken, local legislation and the range of organizations available in a given jurisdiction (Mays and Scutchfield 2010; Taylor-Robinson et al. 2012; Zahner 2005). The patterns of collaborative interactions create networks whose composition and structure influence the distribution of information (Gibbons 2007; Willis et al. 2013). The structure of collaboration networks has also been shown to influence both individual and organizational capacity and goal achievement in many different sectors (Burt 1992; Carpenter et al. 2004; Granovetter 1983, 1985). Thus, a better understanding of network structure in CDP might help improve the effectiveness and efficiency of public health interventions delivery and reduce any duplication of effort.

In this study, we used social network analysis (SNA) to examine interorganizational collaborative relationships in the Canadian preventive health system. SNA has been used to study a wide range of health-related topics (for an overview of the field, see Chambers et al. 2012; Smith and Christakis 2008; Valente 2010), and there is growing interest in developing research on the structure of public health systems with the support of SNA (Barnes et al. 2010; Harris et al. 2008; Leider et al. 2015; Luke and Harris 2007; Varda and Retrum 2012). Our study contributes to this trend by providing a first map of the Canadian CDP collaborative structure. This study drew upon data from the Public Health Organizational Capacity Study (PHORCAST), a repeat census of all public health organizations in Canada.

\section{Methods}

Within the PHORCAST research program, two censuses of all public health organizations engaged in primary CDP at the regional, provincial, territorial and national levels in Canada have been conducted to date (in 2004 and 2010) to measure organizational capacity (defined as skills and resources for CDP) and its determinants and outcomes. Participating organizations were those with mandates for population-wide CDP programming, either through primary prevention of chronic disease (and more specifically, diabetes, cancer, cardiovascular diseases and chronic respiratory illness), healthy lifestyle promotion or a focus on healthy 
eating, tobacco control or physical activity (response rates = 96\% [2004]; 90\% [2010]). These organizations included regional health authorities and public health units/agencies, government departments, national health charities and their provincial/district divisions, other non-governmental and non-profit organizations, para-governmental health agencies (defined as agencies financed by a government, but acting independently of it), resource centres, professional organizations and 'grouped' organizations, such as coalitions, partnerships and alliances. Organizations primarily engaged in secondary or tertiary prevention of chronic disease, advocacy, allocation of funds, fundraising, facilitating joint efforts among organizations and research or knowledge transfer were not eligible. The term 'organization' usually refers to an entire organization. However, the data set also includes some very large, multi-departmental organizations (for example, institutions linked to the federal government). In this specific case, we treated each of the specific departments, units or divisions that undertook CDP activities within those multi-departmental organizations as one distinct 'organization'.

The data on interorganizational collaboration introduced in this paper were collected in the second wave (2010) of the PHORCAST census $(n=207)$. We conducted structured telephone interviews with one key informant per organization identified by a senior manager as the person within the organization most knowledgeable about implementation and delivery of CDP programs, practices, campaigns or activities. In national health charities that had provincial or regional divisions, interviews were conducted within each division that met the inclusion criteria and was judged to be autonomous as an organization.

We used a name generator approach to collect data on interorganizational collaboration. Specifically, informants were asked to identify up to 10 organizations with which their organization had collaborated for CDP activities most often in the past 12 months. There is no consensus on the optimal number of names to elicit in a network survey (Merluzzi and Burt 2013). Methodological work focusing on intraorganizational networks suggests three to six names are adequate to capture interactions and links among people (Marsden 1990). To capture interorganizational relationships among member organizations in the CDP network and to reduce the possibility of a ceiling effect that might constrain the range of data that could be gathered, we chose 10 as the maximum number of names of organizations to elicit. In practice, no respondent provided 10 names, and only $1.5 \%$ of respondents provided nine names, which suggests our limit did not impede identification of additional collaborations. The term 'activities' was defined as programs, projects, initiatives, campaigns or actions aimed at improving chronic disease risk behaviour.

For each organization listed, informants were asked to choose the response(s) that best described the primary purpose of the collaboration. Response choices were: (1) sharing resources to carry out joint projects [R]; (2) sharing information about CDP/healthy life promotion (HLP) actions [P]; (3) sharing information about strategic opportunities (e.g., funding opportunities and legislation) [S]; and (4) other [O] (informants selecting this response were asked to specify the purpose). Informants were asked to exclude any organization considered primarily to be a funder. This typology helps indicate what commodity is being shared through the collaborative 
relationship, but we conceptualize here that all collaborative relationships relate fundamentally to the same phenomenon, whether the commodity is resources or information.

\section{Social Network Analysis}

SNA is the analysis of the relations (ties) that link elements or actors (nodes) within a network (Kadushin 2012; Prell 2012; Robins et al. 2012; Scott and Carrington 2011). In this study, the actors were the CDP public health organizations that participated in the research along with the organizations they identified as collaborators. The ties are any of three types of collaborative relations. In this study, collaboration was assumed to be a reciprocated/ shared act between two parties; the relationships profiled in this network are consequently considered to be undirected. Although mapping a network based only on links confirmed by both collaborators (the organization surveyed and the partners it identifies) could be considered more reliable, including all links indicated by the participants can offer a better representation of the extent of the collaboration network by including potentially weaker but nevertheless existent collaborations between organizations (Barnes et al. 2010; Harris 2013; Provan et al. 2005). It is also common to treat professional collaborative ties as reciprocated. Interorganizational collaborations identified by informants were analyzed using the open source SNA software Cytoscape 3.1.0.

\section{Network measures}

To assess the structural position of each actor in the CDP network, we computed two complementary centrality metrics: degree and betweenness. Centrality is a characteristic of the actors' position related to their importance or contribution in a network (Freeman 1977). The conceptualization and quantification of structural importance are complex issues, and degree and betweenness centrality are two measures, out of several possibilities (Burt 1992; Prell 2012; Wasserman and Faust 1994). Degree centrality is the most simple and straightforward measure, defined as the number of ties connected to a given actor. The number of ties also takes into account the multiple different collaborative ties that organizations might establish with a single partner. CDP actors with higher degree centrality are connected to more partners and/or have a greater number of collaborative relationship ties with their partners; and consequently, they are more 'central' in the network. However, these measures of direct connections can be limited indicators of structural position. For example, a CDP organization might have established several ties with the same group of interconnected organizations, but this does not mean it occupies a strategic position within the whole network. For this reason, we also computed betweenness centrality, a widely used metric to assess how central and structuring an actor is in a network and which is more representative of the real contribution of SNA than the simple counting of each actors' connections.

Betweenness centrality is computed by finding all shortest paths between any given actor pairs in a network and measuring the proportion of all the shortest paths that pass through each actor (Borgatti, Everett and Johnson 2013; Wasserman and Faust 1994). 
Unlike for degree, the number of connections between a pair of actors (based on multiple collaboration purposes) does not matter. Conceptually, betweenness centrality is related to the notion of bridging (Burt 1992). This notion posits that some actors assume key positions in the exchange of information and resources. Actors with high betweenness centrality provide shorter connections between otherwise distant actors or groups. For example, if two groups of densely interconnected organizations are linked through only one organization that belongs to both groups, then this bridging organization will have a crucial role in the connectivity of the network. Betweenness centrality is thus used to understand the strategic advantage of network members and has been linked to efficiency and participation in a network (Burt 1992; Carpenter et al. 2004; Granovetter 1983, 1985; Kadushin 2012). Betweenness centrality scores theoretically range from 0 to 1 , but in large networks, where the total number of shortest paths can be extremely large, these values tend to be very small.

For provincial level network information, we calculated the average degree and betweenness centrality of all the organizations within each province.

\section{Network visualization}

At the network level, our analytical approach focused on the visual analysis of optimized sociograms. In each sociogram, nodes represent actors and lines represent ties between actors. Node colours are a function of the organizations' geographic location (province or territory). Organizations with national or multi-provincial mandates were assigned a node colour distinct from their geographic location. Tie colours reflect the purpose of the collaboration. Node size is a function of each node's betweenness, since this metric is considered a better indicator of the strategic advantage to be gained from structural position. The more central the node, the larger it appears in the figure.

Two algorithms developed by yWorks (http://www.yworks.com/en/company.html) and directly available in Cytoscape 3.1.0 were used to optimize the visual representation of the network. The first, $y$ Files organic, is a "force-directed" graph (Tuikkala et al. 2012) that is optimized based on the principle that nodes are mutually repulsive, while ties constitute attractive forces. On force-directed optimized graphs, repulsive and attractive forces are balanced so that interconnected nodes become positioned close to each other. Nodes with few connections, or those connected with other nodes that in turn have limited connections, will be pushed to the periphery. Highly interconnected nodes will be pushed to the centre of the network, and clusters of interconnected nodes (cliques) will be visible. This process will influence positioning both at the level of the whole graph and within clusters. The second optimization algorithm, $y$ Files orthogonal, minimizes tie crossings and bends. These graphs are optimized in such a way that all ties are sequences of horizontal and vertical segments. By optimizing the tie crossings and bends, this algorithm will also tend to cluster interconnected nodes. Since the mathematical foundations underpinning force-directed and orthogonal algorithms differ, the use of these two graphs allows for triangulation of results.

The study was approved by the Institutional Review Board of the Faculty of Medicine, McGill University, and the Ethics Committee of the University of Montreal Hospital Research Centre (CRCHUM). 


\section{Results}

The resulting map (Figure 1) of Canada's CDP network is the aggregation of 207 ego-centred networks or sets of ties surrounding individual organizations. Through the responses of our initial population of $207 \mathrm{CDP}$ organizations, the survey identified 1,115 additional organizations, providing a total network of 1,322 organizations comprising 33 components or sets of interconnected nodes. Of these, 32 components were isolates, which means they consisted mostly of a single CDP organization that had no direct connection with any of the other CDP organizations surveyed and whose partners were also not connected to any of those organizations (see Figure 1). The remaining component comprised a much larger pan-Canadian network of 1,038 organizations (171 CDP organizations and 867 other partner organizations) totalling $78 \%$ of all organizations identified. Our analysis focuses mostly on this large component.

FIGURE 1. Force-directed sociogram of the CDP network main component

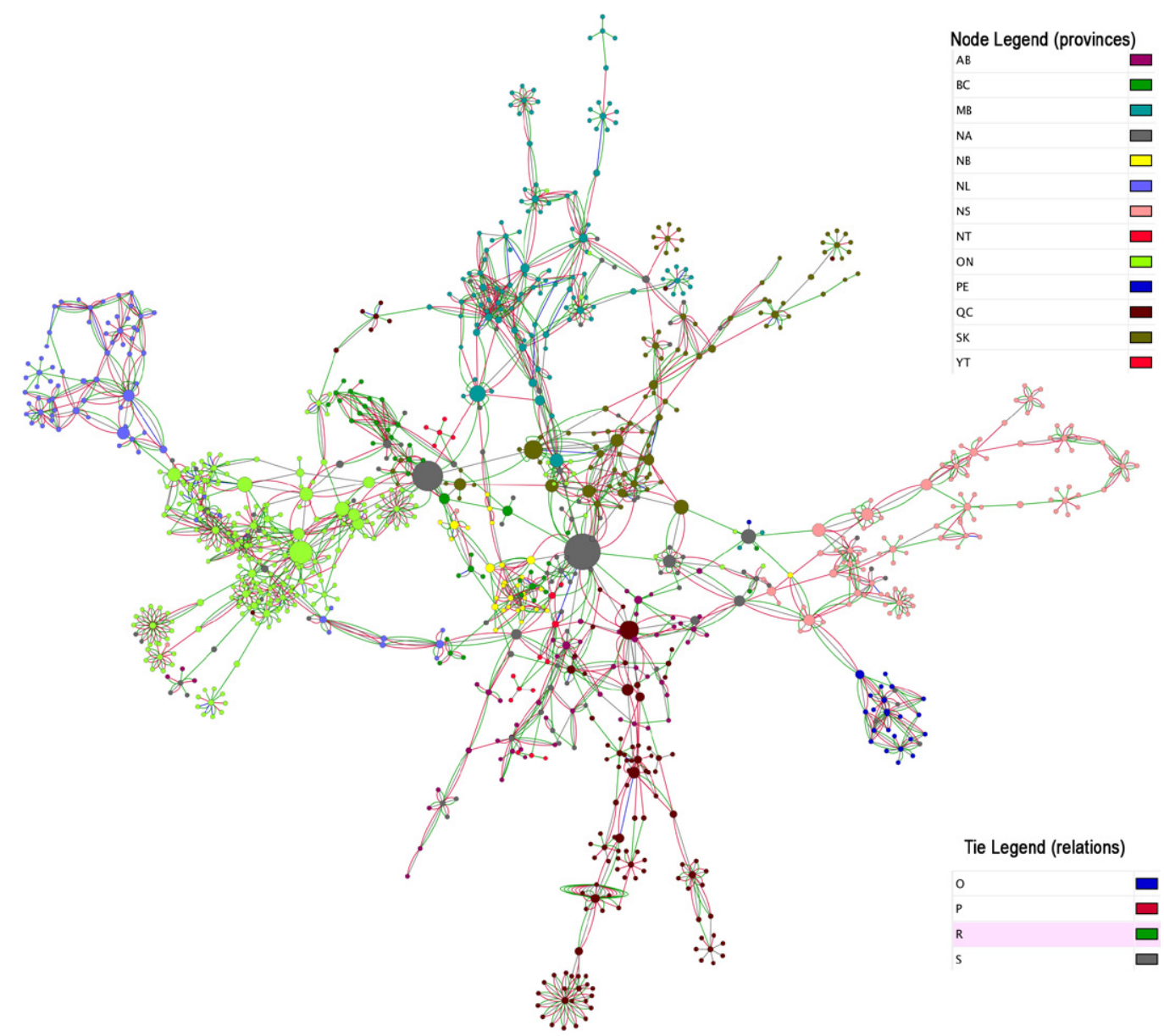

\section{CDP network}

Our sample shows that the number of CDP actors was not distributed evenly across Canada (Table 1). In 2010, Ontario, Quebec and Manitoba had the largest numbers of active CDP organizations per 
province. However, on a per capita basis, Newfoundland, Nova Scotia, Prince Edward Island and Manitoba had the highest numbers, while British Columbia, Quebec and Alberta had the fewest. The variations in the per capita numbers of organizations involved in CDP were quite remarkable, with differences of more than ten-fold between lower- and higher-ranking provinces.

TABLE 1. Network metrics for the main component of the CDP network, Canada, 2010

\begin{tabular}{|c|c|c|c|c|}
\hline \multirow[b]{2}{*}{ Province/Territory* } & \multirow[b]{2}{*}{$\begin{array}{l}\text { Number of CDP } \\
\text { actors }\end{array}$} & \multirow[b]{2}{*}{$\begin{array}{l}\text { Number of CDP actors } \\
\text { per } 100,000 \text { population }\end{array}$} & \multicolumn{2}{|c|}{ Centrality, mean } \\
\hline & & & Degree & Betweenness \\
\hline Yukon & 5 & 144.4 & 1.80 & 0.0015 \\
\hline Northwest Territories & 12 & 273.5 & 3.67 & 0.0058 \\
\hline Prince Edward Island & 24 & 167.7 & 6.75 & 0.0048 \\
\hline New Brunswick & 29 & 38.5 & 5.79 & 0.0080 \\
\hline British Columbia & 43 & 9.5 & 4.79 & 0.0055 \\
\hline Alberta & 54 & 14.5 & 3.83 & 0.0041 \\
\hline Newfoundland & 74 & 144.6 & 5.27 & 0.0068 \\
\hline Saskatchewan & 97 & 92.9 & 4.77 & 0.0133 \\
\hline Nova Scotia & 108 & $1 \mid 4.3$ & 4.19 & 0.0078 \\
\hline Quebec & 114 & 14.4 & 4.10 & 0.0082 \\
\hline Manitoba & 118 & 95.5 & 5.76 & 0.0085 \\
\hline Ontario & 260 & 19.7 & 4.08 & 0.0068 \\
\hline Federal/multi-provincial & 100 & - & 4.71 & 0.0151 \\
\hline Total & 1,038 & - & 4.61 & 0.0084 \\
\hline
\end{tabular}

*There were no organizations from Nunavut eligible to participate in PHORCAST 2010.

\section{Structural network measures by province}

The provincial average number of connections per actor (degree) ranged from $3.8(\mathrm{AB})$ to $6.75(\mathrm{PE})$ (Table 1). This relative uniformity in degree is interesting, given that the number of organizations per province varied by as much as fifty-fold. Provinces with greater numbers of CDP-active organizations did not appear to exhibit higher average numbers of connections per organization than did provinces with fewer CDP-active organizations. Thus, availability of potential partners did not seem to be the limiting factor in developing more collaborations.

Mean provincial betweenness centrality scores also varied in a ten-fold proportion from 0.004 (Alberta) to 0.015 (federal/multi-provincial), with federal/multi-provincial and Saskatchewan having the highest scores. There is a natural tendency for betweenness and degree to co-vary, as the number of paths, and hence, of potential shortest paths, passing through an actor will increase with the total number of connections. In the CDP network studied here, the association between betweenness and number of neighbours (measure of degree without duplicate connections) is relatively weak (correlation 0.348). This level of correlation shows the importance of analyzing both measures of centrality. 


\section{Intraprovincial and interprovincial ties}

Both sociograms produced with force-directed (Figure 1) and orthogonal (Figure 2) algorithms indicate a collaborative structure based largely on intraprovincial connections. Of all the collaboration ties $(2,745)$ reported by the CDP organizations (in the main component), only $17 \%$ (413) are interprovincial. More precisely, $1.1 \%$ of all reported collaboration ties are direct links between two organizations from different provinces, and $16.06 \%$ are between a provincial organization and a federal/multi-provincial organization (see Table 2). The high proportion of intraprovincial connections is evidence that collaboration within the CDP network is occurring more on an intraprovincial level, with the exception of Alberta, whose CDP organizations have almost as many ties with federal/ multi-provincial organizations (70 ties) as with other Albertan organizations (92 ties). Finally, the sociogram shows that most provincial groupings are proximal to a core comprising federal/multi-provincial organizations, some of which have very high betweenness centrality scores, as evidenced by node sizes. Positioned near to this core are several provincial organizations that appear to hold bridging positions connecting their provincial network to broader federal or multi-provincial networks.

FIGURE 2. Orthogonal sociogram of the CDP network main component

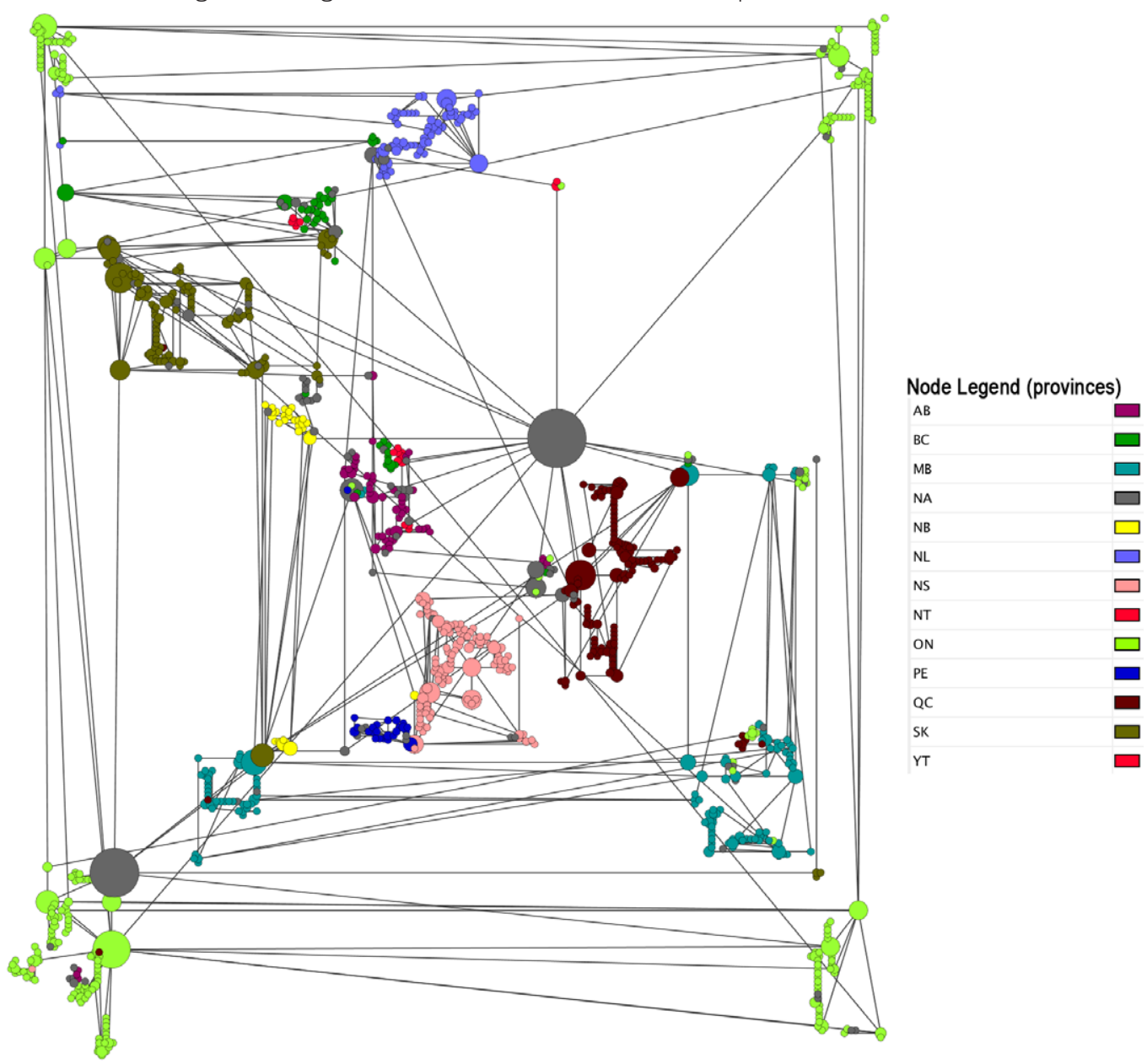


Damien Contandriopoulos et al.

TABLE 2. Number of intraprovincial and interprovincial collaborations in each province

\begin{tabular}{|c|c|c|c|c|c|c|c|c|c|c|c|c|c|}
\hline & NL & $\mathbf{P E}$ & NS & NB & $Q c$ & ON & MB & SK & $\mathrm{AB}$ & BC & YT & NT & $F / M$ \\
\hline NL & 184 & & & & & I & & & & & & & 21 \\
\hline PE & & 71 & 3 & & & & & & & & & & 17 \\
\hline NS & & & 221 & 5 & & I & & & & & & & 11 \\
\hline NB & & & & 92 & & & & & & & & & 13 \\
\hline QC & & & & & 223 & 4 & 4 & 1 & & & & & 37 \\
\hline ON & & & & & & 703 & 3 & 1 & & 3 & & 3 & 57 \\
\hline MB & & & & & & & 321 & I & & & & & 31 \\
\hline SK & & & & & & & & 222 & & I & & & 53 \\
\hline $\mathrm{AB}$ & & & & & & & & & 92 & & & & 70 \\
\hline BC & & & & & & & & & & 151 & & & 52 \\
\hline YT & & & & & & & & & & & 14 & & 3 \\
\hline NT & & & & & & & & & & & & 38 & 17 \\
\hline$F / M$ & & & & & & & & & & & & & 70 \\
\hline
\end{tabular}

$F / M=$ federal/multi-provincial.

\section{Discussion}

This study provides a first map of the collaborative relationships among public health organizations engaged in CDP in Canada. We used SNA to measure the structural properties of this network and to present visually the patterns of connections used for sharing resources and information. On the broader national level, our research points to two findings of value with respect to CDP collaborations. The first is the clear evidence that collaboration between CDP organizations is overwhelmingly intraprovincial. Since health is a provincial responsibility in Canada, and given that most CDP is funded through provincial programs, the tendency of CDP-active organizations to collaborate within their own province is not so surprising. Of more interest is the second finding on the centrality and bridging role of federal/multiprovincial organizations. Our results show that direct collaboration across provinces is almost non-existent, even between bordering provinces. The extra-provincial connectivity of provincial CDP organizations rests almost exclusively on ties with federal/multi-provincial organizations. Given their interprovincial mandates, it was expected that federal and multi-provincial organizations would exhibit the highest betweenness scores and serve as bridges within the network, but we did not expect they would be almost the only ones playing this role. Overall, the strong intraprovincial networking pattern and the extra-provincial links established mostly with federal/multi-provincial organizations support the idea that legislative boundaries are more likely to explain patterns of CDP collaboration than are factors such as geographic proximity.

Also of interest for understanding the whole network structure is the low correspondence between the average number of collaborators per organization and the number of 
organizations in each province. This suggests that the CDP organizations' actual number of partners does not depend on the number of potential available partners. A better understanding of the factors explaining why in some provinces CDP organizations achieve a higher level of collaboration would be interesting. Finally, it should also be noted that a small number of organizations seem to function in relative isolation and are either not connected or only remotely connected to the national network. Several hypotheses could explain this phenomenon. For example, studies on public health organizational networks have suggested that organizations in smaller rural areas tend to have access to a narrower range of possible partners and thus collaborate more closely with specific partners (Mays and Scutchfield 2010). As specified in the limitations section, it is also possible that the organizations that are among these isolates forgot to disclose certain collaborative links that would have linked them to the main component.

On a provincial level, our data shows that CDP organizations in British Columbia and Alberta may have weaker structural positions, with low per capita numbers of organizations, relatively low average numbers of networking connections between organizations and low average betweenness centrality. Conversely, organizations in Saskatchewan, Manitoba and the Maritimes (apart from Prince Edward Island) seem to hold stronger positions, having higher per capita numbers of organizations and higher mean degree and betweenness centralities than other provinces. Finally, despite having the largest number of organizations and occupying a central geographic location, Ontario does not appear to hold as central a position as the absolute number of CDP organizations would lead us to believe.

In practical terms, our findings indicate that federal and multi-provincial organizations play (or at least could play) key roles in shaping CDP practices, given their highly central and bridging positions. As mentioned earlier, empirical and theoretical evidence suggests that both number of partners and centrality in a network are linked to individual and organizational success (Burt 1992; Carpenter et al. 2004; Granovetter 1983, 1985). Other studies on public health systems also stress the importance of occupying central positions in a network (Provan et al. 2005; Wholey et al. 2009). Organizations in central bridging positions can diffuse information effectively and have a major role in promoting best practices. Additionally, central actors can develop into hubs of expertise to keep less connected organizations abreast of what is going on elsewhere. Therefore, federal and multi-provincial CDP-active organizations with high connectivity and centrality could be instrumental in developing programs and facilitating funding opportunities that further interprovincial collaboration - something that is likely to strengthen CDP capacity in Canada.

\section{Limitations of the study}

We believe the CDP network presented in this study is a fair representation of the Canadian CDP structure, as it is based on a national census of organizations comprising the preventive health system (Hanusaik et al. 2010, 2014). However, as there were certain limitations in the data collection process, some variations in CDP structure could occur 
in other iterations of this study. First, the data on collaborative links was obtained from a single key informant per organization and was based on each informant's personal account of the organization's collaborative relations. Thus, some collaborative links may have been omitted or forgotten. Such overlooked collaborative links might explain why 32 components are isolated from the main CDP network, and the main component would probably include additional links if we had interviewed a second round of informants in each organization. Nevertheless, responses were elicited from carefully selected informants identified as being the most knowledgeable about the implementation of CDP programming. Moreover, "selfreporting" is one of the most common methods of social network data collection (Heath et al. 2009; Podsakoff and Organ 1986). By focusing on perceived relations, this method also has the advantage of calling attention to the relations deemed meaningful by the participants in the study.

A second limitation of this study concerns network boundaries. The structure of the network could vary if the boundaries were expanded to include collaborators of the partner organizations identified by the core CDP organizations that participated in our study. As such, the network presented in this study is a bounded extraction from a limitless network (Knoke and Yang 2008; Wasserman and Faust 1994). Practically, however, mapping a larger network from the recursive identification of contacts (systematic snowballing) was beyond the scope of this study, since it would have meant including all organizations with which CDP organizations frequently collaborate, including those that do not themselves have CDP as a primary mandate. The goal of our study was to highlight the collaborative structure established by the primary organizations involved in CDP only $(n=207)$.

A third limitation is that the CDP network introduced in this paper represents a set point in time. A longitudinal analysis based, for example, on retrospective self-reported collaborations, would help assess the level of stability and permanence of CDP collaborative networks. Further studies on the same organizations would be necessary to confirm whether limited interprovincial collaborations are an enduring characteristic of the Canadian CDP network. Lastly, for the sake of brevity, we did not differentiate among the different purposes of collaboration in our network analysis, but this could be an interesting addition to further understanding CDP collaboration structures.

\section{Conclusion}

One of the main contributions of this study is to present a case study pointing to specific characteristics of the CDP network that should be investigated further to increase our understanding of the determinants of CDP capacity at the national level. We contend that CDP capacity should not be conceived as the sum of discrete CDP-active organizations' capacities, but rather as a more complex ecology of interconnected organizations whose overall influence is shaped by the ways in which they are interconnected and collaborate. This approach is especially significant, since it can help identify new ways to foster more effective CDP practices. 
First, mapping the preventive health system, as done in this study, is a way to identify the most strategically connected provincial or federal/multi-provincial groups of organizations, which can then be used as vectors to transfer resources, information or the best practices. Such a method could thus be beneficial to provincial decision-makers to identify what networking relations exist in their province and to identify the organizations that could, given their structural position, play a central role in health prevention and promotion networks. Second, the major differences found in this study regarding the per capita numbers of organizations involved in CDP and the average structural position of organizations in each province call for a better understanding of the associations between provincial CDP capacity, structural position and CDP intervention outcomes. Analyzing how structural position might affect CDP interventions and, ultimately, population-level health outcomes, could be an invaluable indicator in allocation decision processes at both provincial and federal levels. Little is known about the structures of preventive health systems and about how these structures articulate with CDP capacity and outcomes. The case study presented here provides one example of how SNA can be productively used to develop this research area.

\section{Acknowledgements}

This study was supported by the Canadian Institutes of Health Research (SEC 117124). Damien Contandriopoulos holds a CIHR Applied Public Health Chair. Katerina Maximova holds a Career Development Award in Prevention Research funded by the Canadian Cancer Society (grant number 702936). Jennifer O'Loughlin holds a Canada Research Chair in the Early Determinants of Adult Chronic Disease.

The authors wish to thank Catherine Larouche, $\mathrm{PhD}$ candidate in Anthropology at McGill University, for her technical help in finalizing this article.

Correspondence may be directed to: Damien Contandriopoulos, University of Montreal, Faculty of Nursing, P.O. Box 6128, Centre-ville Station, Montreal, QC H3C 3J7; e-mail:damien.contandriopoulos@gmail.com.

\section{References}

Barnes, M., J. MacLean, and L. Cousens. 2010. “Understanding the Structure of Community Collaboration: The Case of one Canadian Health Promotion Network." Health Promotion International 25(2): 238-47.

Birt, C. and A. Foldspang. 2011. European Core Competences for Public Health Professionals (ECCPHP). ASPHER Publications No. 5. Brussels: Association of Schools of Public Health in the European Region (ASPHER). Retrieved August 6, 2015. <http://www.aspher.org/foto/BULLETIN032014/EPHCCP_ECC_PH-Professionals.pdf>.

Bjegovic-Mikanovic, V., K. Czabanowska, A. Flahault, R. Otok, S. Shortell, W. Wisbaum and U. Laaser. 2014. Addressing Needs in the Public Health Workforce in Europe: Policy Summary 10. Copenhagen, Denmark: World Health Organization (WHO). Retrieved August 6, 2015. <http://www.euro.who.int/__data/assets/ pdf_file/0003/248304/Addressing-needs-in-the-public-health-workforce-in-Europe.pdf $>$.

Borgatti, S.P., M.G. Everett, and J.C. Johnson. 2013. Analyzing Social Networks. Thousand Oaks, CA: Sage Publications.

Burt, R.S. 1992. Structural Holes: The Social Structure of Competition. Cambridge, MA: Harvard University Press. 
Butterfoss, F.D., R.M. Goodman and A. Wandersman. 1993. “Community Coalitions for Prevention and Health Promotion." Health Education Research 8(3): 315-30.

Carpenter, D.P., K.M. Esterling and D.M.J. Lazer. 2004. "Friends, Brokers, and Transitivity: Who Informs Whom in Washington Politics?" Journal of Politics 66(1): 224-46. doi:10.1046/j.1468-2508.2004.00149.x.

Centers for Disease Control and Prevention (CDC). 2015. National Public Health Performance Standards (NPHPS). Retrieved July 8, 2016. <https://www.cdc.gov/nphpsp/>.

Chambers, D., P. Wilson, C. Thompson and M. Harden. 2012. "Social Network Analysis in Healthcare Settings: A Systematic Scoping Review." PLoS ONE 7(8): e41911.

Frank, J., E. DiRuggiero and B. Moloughney. 2003. The Future of Public Health in Canada: Developing a Public Health System for the 21st Century. Toronto, ON: Canadian Institutes of Health Research; Institute of Population and Public Health.

Freeman, L.C. 1977. "A Set of Measures of Centrality Based on Betweenness." Sociometry 40(1): 35-41. doi:10.2307/3033543.

Gibbons, D.E. 2007. “Interorganizational Network Structures and Diffusion of Information through a Health System." American Journal of Public Health 97(9): 1684-92.

Granovetter, M. 1983. “The Strength of Weak Ties: A Network Theory Revisited." Sociological Theory 1(1): 201-33. Retrieved August 6, 2015. <http://www.soc.ucsb.edu/faculty/friedkin/Syllabi/Soc148/ Granovetter\%201983.pdf>.

Granovetter, M. 1985. "Economic Action and Social Structure: The Problem of Embeddedness." American Journal of Sociology 91(3): 481-510. Retrieved August 6, 2015. <https://www2.bc.edu/ jonescq/mb851/Feb26/ Granovetter_AJS_1985.pdf>.

Hanusaik, N., D. Contandriopoulos, N. Kishchuk, K. Maximova, G. Paradis and J.L. O'Loughlin. 2014. "Chronicling Changes to the Chronic Disease Prevention Landscape in Canada's Public Health System 2004-2010." Public Health 128(8): 716-24. doi:10.1016/j.puhe.2014.05.016.

Hanusaik, N., J.L. O'Loughlin, N. Kishchuk, G. Paradis and R. Cameron. 2010. “Organizational Capacity for Chronic Disease Prevention: A Survey of Canadian Public Health Organizations." European Journal of Public Health 20(2): 195-201. doi:10.1093/eurpub/ckp140.

Harris, J.K. 2013. “Communication Ties across the National Network of Local Health Departments." American Journal of Preventive Medicine 44(3): 247-53.

Harris, J.K., D.A. Luke, R.C. Burke and N.B. Mueller. 2008. "Seeing the Forest and the Trees: Using Network Analysis to Develop an Organizational Blueprint of State Tobacco Control Systems." Social Science E Medicine 67(11): 1669-78.

Heath, S., A. Fuller and B. Johnston. 2009. "Chasing Shadows: Defining Network Boundaries in Qualitative Social Network Analysis." Qualitative Research 9(5): 645-61. doi:10.1177/1468794109343631.

Kadushin, C. 2012. Understanding Social Networks: Theories, Concepts, and Findings. Oxford, UK: Oxford University Press.

Knoke, D. and S. Yang. 2008. Social Network Analysis. Thousand Oaks, CA: SAGE Publications.

Leider, J.P., B.C. Castrucci, J.K. Harris and S. Hearne. 2015. “The Relationship of Policymaking and Networking Characteristics among Leaders of Large Urban Health Departments." International Journal of Environmental Research and Public Health 12(8): 9169-80.

Luke, D.A. and J.K. Harris. 2007. "Network Analysis in Public Health: History, Methods, and Applications." Annual Review of Public Health 28(1): 69-93.

Marsden, P.V. 1990. “Network Data and Measurement." Annual Review of Sociology 16: 435-63. Retrieved August 6, 2015. <http://www.umass.edu/pathway/nopassword/networkreliability2.pdf>. 


\section{Mapping Collaborative Relations among Canada’s Chronic Disease Prevention Organizations}

Mays, G.P. and F.D. Scutchfield. 2010. “Improving Public Health System Performance through

Multiorganizational Partnerships." Preventing Chronic Disease 7(6): A116. Retrieved August 6, 2015. <http:// www.cdc.gov/pcd/issues/2010/nov/10_0088.htm>.

Merluzzi, J. and R.S. Burt. 2013. "How Many Names Are Enough? Identifying Network Effects with the Least Set of Listed Contacts." Social Networks 35(3): 331-37. doi:10.1016/j.socnet.2013.03.004.

National Collaborating Centre for Determinants of Health. (NCCDH) 2010. Integrating Social Determinants of Health and Health Equity into Canadian Public Health Practice: Environmental Scan 2010. Antigonish, NS: National Collaborating Centre for Determinants of Health, St. Francis Xavier University. Retrieved August 6, 2015. <http://nccdh.ca/images/uploads/Environ_Report_EN.pdf>.

Podsakoff, P.M. and D.W. Organ. 1986. "Self-Reports in Organizational Research: Problems and Prospects." Journal of Management 12(4): 531-44. doi:10.1177/014920638601200408.

Prell, C. 2012. Social Network Analysis. History, Theory \& Methodology. London, UK; Thousand Oaks, CA: SAGE. Provan, K.G., M.A. Veazie, L.K. Staten and N.I. Teufel-Shone. 2005. “The Use of Network Analysis to Strengthen Community Partnerships." Public Administration Review 65(5): 603-13.

Public Health Agency of Canada (PHAC). 2007. Core Competencies for Public Health in Canada. Release 1.0. Ottawa, ON: Author. Retrieved August 6, 2015. <http://www.phac-aspc.gc.ca/php-psp/ccph-cesp/pdfs/cc-manual-eng090407.pdf>. Robins, G., J.M. Lewis and P. Wang. 2012. "Statistical Network Analysis for Analyzing Policy Networks." Policy Studies Journal 40(3): 375-401.

Roussos, S.T. and S.B. Fawcett. 2000. "A Review of Collaborative Partnerships as a Strategy for Improving Community Health." Annual Review of Public Health 21(1): 369-402. doi:10.1146/annurev.publhealth.21.1.369.

Scott, J. and P.J. Carrington. 2011. The SAGE Handbook of Social Network Analysis. London, UK: SAGE.

Simon, P.A. and J.E. Fielding. 2006. "Public Health and Business: A Partnership that Makes Cents." Health Affairs 25(4): 1029-39. doi:10.1377/hlthaff.25.4.1029

Smith, K.P. and N.A. Christakis. 2008. "Social Networks and Health." Annual Review of Sociology 34(1): 405-29.

Taylor-Robinson, D.C., F. Lloyd-Williams, L. Orton, M. Moonan, M. O'Flaherty and S. Capewell. 2012.

"Barriers to Partnership Working in Public Health: A Qualitative Study." PLoS ONE 7(1): e29536. doi:10.1371/ journal.pone.0029536

Tuikkala, J., H. Vähämaa, P. Salmela, O. Nevalainen and T. Aittokallio. 2012. “A Multilevel Layout Algorithm for Visualizing Physical and Genetic Interaction Networks, with Emphasis on their Modular Organization." BioData Mining 5: 2. doi:10.1186/1756-0381-5-2.

Valente, T. W. 2010. Social Networks and Health: Models, Methods, and Applications. New York, NY: Oxford.

Varda, D.M. and J.H. Retrum. 2012. "An Exploratory Analysis of Network Characteristics and Quality of Interactions among Public Health Collaboratives." Journal of Public Health Research 1(2): 170-76. doi:10.4081/jphr.2012.e27.

Wasserman, S. and K. Faust. 1994. Social Network Analysis: Methods and Applications. Cambridge, UK:

Cambridge University Press.

Wholey, D.R., W. Gregg and I. Moscovice. 2009. "Public Health Systems: A Social Networks Perspective." Health Services Research 44(5p2): 1842-62.

Willis, C.D., B.L. Riley, C.P. Herbert and A. Best. 2013. "Networks to Strengthen Health Systems for Chronic Disease Prevention." American Journal of Public Health 103(11): e39-48. doi:10.2105/AJPH.2013.301249.

Zahner, S.J. 2005. "Local Public Health System Partnerships." Public Health Reports 120(1): 76-83. Retrieved August 6, 2015. <http://www.publichealthreports.org/issueopen.cfm?articleID=1434>. 